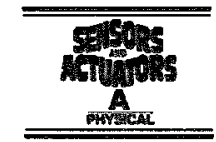

\title{
High-resolution shadow-mask patterning in deep holes and its application to an electrical wafer feed-through
}

\author{
G.J. Burger ${ }^{\text {a,* }}$, E.J.T. Smulders ${ }^{\text {a }}$, J.W. Berenschot ${ }^{\text {a }}$, T.S.J. Lammerink ${ }^{\text {a }}$, J.H.J. Fluitman ${ }^{\text {, }}$, \\ S. Imai ${ }^{\mathbf{b}}$ \\ MESA Research Institule. Universily of Twense. PO Bax 217.7500 AE Enschede, Netherlands \\ "Mechumical Engineering Reseurch Laburutory. Hitachi Lid. 502. Kandatsu, Tsuchiura, Ibaraki 300, Japun
}

\begin{abstract}
Hibstract
This paper presents a technique to patlern materials in deep holes and/or on non-planar substrate surfaces. A rather old technique, namely, electron-beam evaporation of metals through a shadow mask, is used. The realization of high-resolution shadow masks using micromachining techniques is described. Further, a low ohmic electrical wafer fred-:hrough with a small parasitic capacitance to the substrate and a high placing density is presented.
\end{abstract}

Keywords: Shadow masks: Feed-throughs: Patterning: Contacting: Microrrachining

\section{Introduction}

High-resolution patterning in deep holes and/or on nonplanar ( $>10 \mu \mathrm{m}$ ) substrate surfaces is an often-encountered problem in micromechanics. The main cause of this problem is that normal resist spinning cannot be used on such a substrate. But even if spray-on resist or spin-on photosensitive polyimide is used, the pattern resolution is limited by the lithographic resolution in a deep hole, which additionally may be interfered with by optical reflections in the hole. The high pattern resolutions presented in this paper are realized by electron-beam evaporation of metals through a shadow mask [1]. The use of micromachining techniques for the realization of the shadow mask, together with recently developed aligning and bonding tools, significantly improve the pattern resolution and alignment accuracy.

\section{Method}

Evaporation is done by heating a source of the desired material under high-vacuum conditions $\left(<10^{-3} \mathrm{~Pa}\right)$ to its melting temperature. In this pressure range the mean free path of the vapour atoms is much larger $(>10 \mathrm{~m})$ than the distance of the source to the substrates. Therefore the vapour atoms stream in straight lines radially from the source to the sub-

\footnotetext{
* Corresponding author. Phone: + 3153 892241. Fax: + 31 534358259
}

strate. If a 'shadow mask' is brought between the source and the substrate the 'shadow' pattern is transferred to the deposited layer, see Fig. 1(a). It is obvious that the deposited pattern is always larger than the pattern in the shadow mask. The enlargement $(E)$ can easily be calculated from the geometry of the evaporation equipment. In most equipment this enlargement will be of the order of $0.1 \%$ (e.g., $c=0.5 \mathrm{~m}$, $d=0.5 \mathrm{~mm} \Rightarrow E=1.001$ ). On wafer scale this means a deviation of the order of several tens of microns. Another deviation in the deposited pattem is illustrated in Fig. 1(b). When the substrate and shadow mask are not placed esactly perpendicular to the vapour stream, the pattern will be shifted.

a)

a) $a$

b)

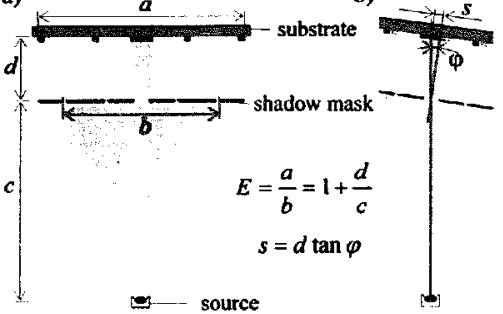

Fig. I. Electron-beam evaporation through a shadow mask: (a) enlargement of the patten (E): (b) shift due to roration (s). 
An angle of $1^{\circ}$ gives a pattern shift of $10 \mu \mathrm{m}(d=0.5 \mathrm{~mm})$. Therefore the positioning of the substrate should be arranged carefully for accurate pattern definition.

If we focus on the edge of a deposited pattern we find a smooth decay (spreading) in layer thickness, see Fig. 2 . This is mainly because the vapour source is not a point source, which results in a penumbra region near the edge of the patterns.

Another reason for spreading is that if the sticking coefficient cf the vapour atoms is lower than unity, they will scatter at the mask edge and/or the substrate [2]. These scattered atoms may be deposited under the shadow mask. Both effects result in an undesired thin film of evaporation material in the shadow regions. However, since this spreading is much thinner than the desired pattern, it can easily be removed by dipping the substrate in a appropriate etch solution.

To determine the maximal resolution, tracks of aluminium were deposited through a shadow mask with slits of different widths. Fig. 3 shows the nomalized track thickness as a function of the split width at different deposition rate $(r)$ and mask-substrate spacing $(d)$. At small slit width the thickness drops drastically, which indicates the non-point-source effect. The resolution is determined by the slit width at which the layer thickness is comparable with the maximum value. It is clear that the resolution depends strongly on the mask-sub-

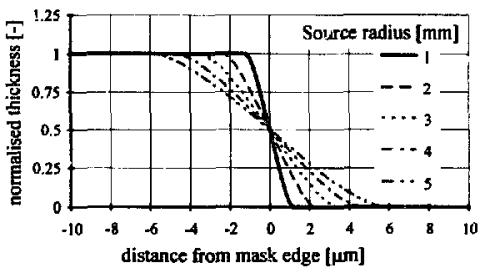

Fig. 2. Cal culated thickness profile near the edge of a partem deposited f. om a circular source. A uniform ernission over the source area is assumed. The source-mask distance (c) is $350 \mathrm{~mm}$ and the mask-substmate spacing (d) is $0.38 \mathrm{~mm}$.

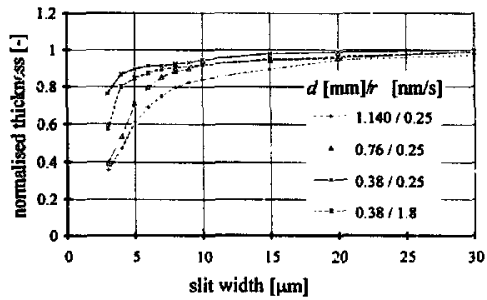

Fig. 3. Relative track thickness of aluminitum tracks deposited through a slit. Process parameters: source-substrate distance, 350 mij; background pressure. $6 \times 10^{-4} \mathrm{~Pa}$ : source radius, $=2 \mathrm{~mm}$; mask-substrats spacing, $d$ deposition rate. $r$.
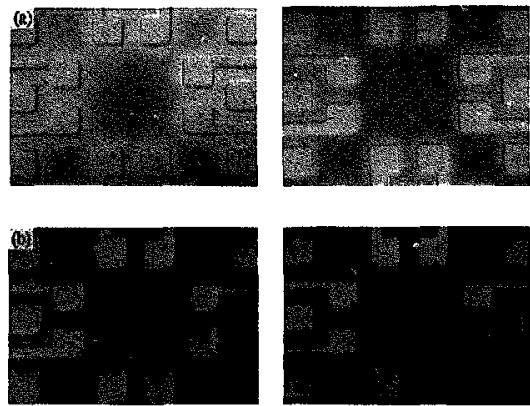

Fig. 4. Sprcading around deposited aluminium pattems: (a) as deposited; (b) after $60 \mathrm{~s}$ etching in an NaOH solution. Deposition rate: lef, $1.8 \mathrm{~nm}$ $\mathrm{s}^{-1}$; right, $0.25 \mathrm{~nm} \mathrm{~s}^{-1}$.

strate spacing; however, a resolution of $3 \mu \mathrm{m}$ can easily be achieved.

At higher slit width the thickness gradually reaches the maximum; this indicates the scattering effect. Fig. 4(a) is an illustration of the spreading due to scaltering. It can be seen that the spreading depends on the deposition rate. Lower deposition rates give a better patten definition, but the surface roughness of the deposited layer is much larger. Fig. 4(b) shows the structures after a short dip in an appropriate etchant. The resulting structures are well defined without spreading caused by scattered atoms.

\section{Shadow masks}

Shadow-mask patterning was (is) a very important tool in thin-film processing of components, such as resistors, resistor arrays and capacitance-end electric circuitry on a large variety of substrates. Usually the masks are realized in metal or graphite sheets by, e.g., milling, arc erosion or laser cutting. The smallest aperture can be around $50 \mu \mathrm{m}$ with a tolerance of $5 \mu \mathrm{m} \mathrm{[1].} \mathrm{The} \mathrm{limitations} \mathrm{in} \mathrm{resolution} \mathrm{and} \mathrm{the} \mathrm{topical}$ constraints on shadow masks (circular connected patterns cannot be used because the inside should be supported) are responsible for the inapplicability in normal micromachining processes. However, shadow masks can be useful in cases where normal patterning (lithography) is difficult.

The shadow masks presented in this paper are realized by using bulk-micromachining techniques (see Fig. 5). With this, a smaltest aperture of $2 \mu \mathrm{ra}$ with a tolerance of $0.5 \mu \mathrm{m}$ can be obtained. The deposited pattern resolution in a typical cvaporation set-up can be around $5 \mu \mathrm{n}(d<0.5 \mathrm{~mm})$. The spreading near the pattern edgus can also be of advantage because the area under a small beam (e.g., $2 \mu \mathrm{m}$ width) of the shadow mask will be covereit completely if the spreading is larger than the width of the leeam. In this way a circular 


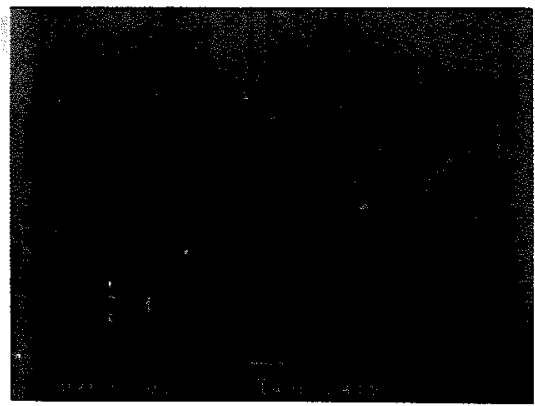

Fig.5. Micromachined shadow mask; this mask is used for the pattern shown in Fig. 7.

connected pattern can be realized by suspending the inside part of the mask by beams of $2 \mu \mathrm{m}$ width.

Here, two shadow masks are evaluated, namely a silicon shadow mask and an integrated shadow mask.

\subsection{Silicon shadow mask}

The shadow mask is made of $a<100>$-oriented silicon wafer (see Fig. 6(a)-(c), left). The shadow pattern is anisotropic dry etched (RIE) $\pm 25 \mu \mathrm{m}$ deep [3] and covered with LPCVD silicon nitride $(0.5 \mu \mathrm{m})$ (a). Then membranes are etched ( $25 \%$ aqueous $\mathrm{KOH}$ solution at $75^{\circ} \mathrm{C}$ ) from the hackside till the shadow pattern is clearly visible (b). Finally, the silicon nitride membranes are removed by dry etching (RIE) (c). The etch time in the $\mathrm{KOH}$ is not very critical because the shadow pattern is etched anisotropically, therefore the shadow image will not change due to over-etching. Fig. 5 gives an illustration of a reaiized shadow mask.
To bond the shadow mask onto the substrate, a few droplets of photoresist are deposited near the edge of the shadow mask and the mask is spun at $1000 \mathrm{mpm}$. After a short pre-bake (5 $\min , 90^{\circ} \mathrm{C}$ ) the two wafers are aligmed and fyed, using a mask aligner with aligned-bonding facilities (Electronic vision, AL-6). The actual bonding is done by heating the package to $150^{\circ} \mathrm{C}$ for $20 \mathrm{~min}$ in nitrogen ambient. As.er evaporation of the desired material, the mask can be removed by exposing the package to an oxygen plasma at $120^{\circ} \mathrm{C}$ for about $30 \mathrm{~min}$.

\subsection{Integrated shadow mask}

Here the shadow mask is integrated in the same substrate on which it is needed. For example, a KOH under-etched beam may act as a shadow mask for the underlying hole or channel (e.g., see Fig. 9). This is a very elegant usage of the shadow-mask principle because of its simplicity and because there is no need for alignment with the etched structures. However, the available patterns and applicability to electrical contacting are limited.

\section{Applications}

Several electrical wafer feed-throughs are found in the literature [4,5]. Most of these are rather large because generally each connection needs a hole through the wafer. Therefore the coniact density is low $\left(\approx 1 \mathrm{~mm}^{-2}\right)$ and the connections have a high parasitic capacitance to the substrate. Multiple connection tracks through one hole can easily be realized with the shadow-mask method. Fig. 6 shows the basic process steps of the realization of the feed-through contacts.

First the feed-through holes are etched (25\% aqueous $\mathrm{KO}$. solution at $75^{\circ} \mathrm{C}$ ) down to a silicon nitride membrane a)

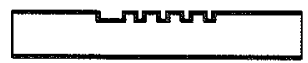

b)

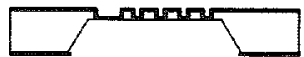

c)

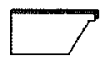

d)
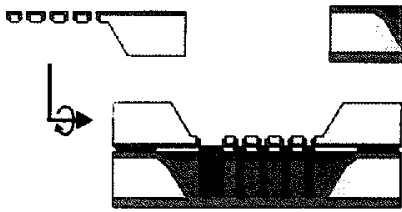

e)
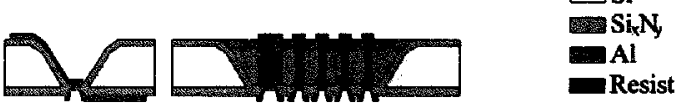

Fig. 6. Process scheme of the electric wafer feed-through using a silicon shadow mask. 
(a). The silicon nitride membrane is removed and a short etch dip (KOH) provides for smooth hole edges (b). An LPCVD silicon nitride layer is grown for electrical insulation (c). A silicon shadow mask is bonded onto the substrate, as described before, and the aluminium tracks are deposited (d). After removing the shadow mask, small connection holes are etched in the silicon nitride membranes from the other side of the wafer and the connection layer is deposited (c). Prior to this deposition the spreading may be removed. The electric connection may be disturbed due to a thin native oxide layer between the two metal layers. The connection can be improved by an anneal step at $450^{\circ} \mathrm{C}$ for $15 \mathrm{~min}$. For this application the deviation (shift) of the pattern deposited on the membrane, due to a misalignment of the substrate with respect to the vapour stream, is not harmful because the succeeding pattern steps can easily be aligned to the pattern on the membranes.

Fig. 7 shows an SEM photograph of the realized feed. throughs. Table I gives the typical specifications of an electric connection with tracks of $10 \mu \mathrm{m}$ width through a $380 \mu \mathrm{m}$ thick wafer.

Using this process a pattern resolution in the hole of $3 \mu \mathrm{m}$ is achieved and a large variety of patterns can be deposited. Fig. 8 shows an example of a coil deposited in a hole.

A wafer feed-through can also be realized with an integrated shadow mask, see Fig. 9. The actual silicon nitride shadow mask is deposited prior to the silicon nitride KOH etch mask. After $\mathrm{KOH}$ etching of the hole and removal of the etch mask, the silicon nitride shadow mask is left above the hole. Now a short isotropic silicon etch provides for a

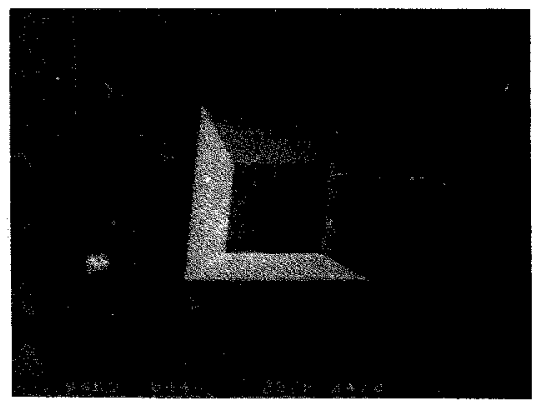

Fig. 7. Realized feed-throughs, the hole is $380 \mu \mathrm{m}$ deep and covers an area of approximately $!$ mun $\times 1$ inm, the 36 signal tracks are $10 \mu \mathrm{m}$ wide and the silicon nitride insulatiori isyer is $0.5 \mu \mathrm{m}$ thick.

\section{Table I}

Specifications of the realized feed-throughs

\begin{tabular}{lll}
\hline $\begin{array}{l}\text { Resistance } \\
{[\Omega]}\end{array}$ & $\begin{array}{l}\text { Capacilance } \\
{[\mathrm{pF}]}\end{array}$ & $\begin{array}{l}\text { Contact density } \\
\left.\text { [number } / \mathrm{mm}^{2}\right]\end{array}$ \\
\hline$<5$ & $<1$ & 36 \\
\hline
\end{tabular}

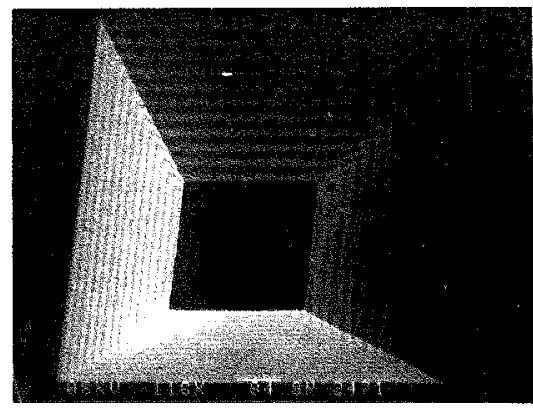

Fig. B. A coil in a hole with a track $10 \mu \mathrm{m}$ wide (seen from above).

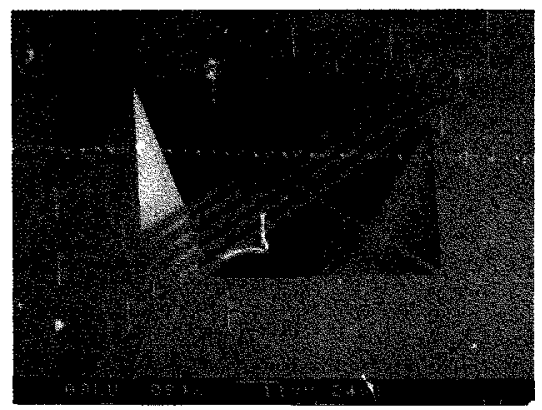

Fig. 9. A foed-through realized with a integrated shadow mask.

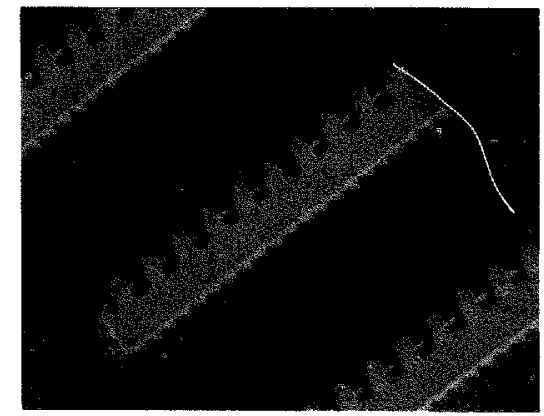

Fig. 10. Inclined silicon oxide beams for a vibro-actuated micromover.

deepened trail under the shadow mask. After deposition of the desired metal, the tracks deposited in the trail will be disconnected from the top surface. 
The integrated shadow-mask technique has also been applied successf.ity in the realization of the carrier bearn structure of a vibro-actuated micromover [6], see Fig. 10. Here, a silicon nitride mask was subsequently used as a $\mathrm{KOH}$ etch mask, as a diffusion mask during oxidation and as a shadow mask during aluminium deposition. HF etching was used to pattern the silicon oxide. After etching of aluminium, nitride and silicon, the structure shown in Fig. 10 is obtained.

\section{Conclusions}

Evaporation of metals through a shadow mask is used for high-resolution patterning in deep holes. The presented micromachined masks and aligaing process significantly improve the practical resolution of shadow-mask panteming. A resolution of $3 \mu \mathrm{m}$ in a hole $380 \mu \mathrm{m}$ deep is demonstrated. The technique was successfully applied to a high density. low-ohmic electrical wafer feed-through.

\section{References}

[I] R. Glang and L.V. Gregor, Generaticn of patterns in thin films, Handbook of Thin-jitm Technology, McGraw-Hill, New York, 1970. pp. 7-1-7-10.

[2] S. Gray and P.K. Weimer, Production of fine patterns by eyaponation, RCA Review, 20 (1959) 413-425.

[3] H.V. Jarsen, M.J. de Boer, R. Legtenberg and M. Elwenspoek. The black silicon method: a universal method for determining the parameter setting of a fluorine-based reaclive ion etcher in deep silicon trench

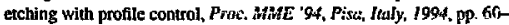
64.

[4] M. Esashi. Micromachining for packaged sensors, Proc. 7th Int. Conf. Solid-Stuie Sinsors and Actuators (Transducers 93), Yokohama. Japan. 7-10 June, 1993, pp. 260-265.

[5] S. Linder, H. Baltus, F. Gnaedinger and E. Doering, Fabrication technology for wafer through-hole inteiconnections and threedimensional stacks of chips and wafers, Proc. 7th IEEE Workshop on Micro Electro Mechanical Systems, MEMS '74, Oiso, Japan, January. 1994, pp. 349-354.

[6] B.J.T. Smulders, to be published.

\section{Biographies}

Gert-Jan Burger was born on June 2, 1965, in Heerhugowaard, The Netherlands. He received his M.Sc. degree in electrical engineering from the University of Twente in 1990. In 1991 he joined the micromechanics group of the MESA Research Institute. His research interest is the measurement of tribological aspects of rigid disk storage devices.
Edwin J.T. Sinulders was born on December 8, 1966, in Tilburg, The Netherlands. He received his M.Sc. degree in physics from the University of Utrecht in 1991. Since 1993 he has been involved with research on a microphositionez at the micromechanics group of the MESA Research Institue.

Enwin W. Berenschot was born on December 13, 1967, in Winterswijk, The Netherlands. He received his B.Sc. degree in applied physics from the Technical High School of Enschede in 1990. Since 1992 he has worked in the micromechanics group of the MESA Research Instinue. He is mainly occupied with clean-roon technology, research on and development of new fabrication techniques, and characterization of devices.

Theo S.J. Lammerink was born on October 28, 1956, in Haarle, The Netherlands. He received his M.Sc. degree in electrical engineering from the University of Twente in Enschede in 1982. In 1983 be joined the transducers and materials science group as assistant professor. He received his Ph.D. in 1990 in the field of optical and micromechanical transducers and transducer systems. Currently he is involved in research and development of micro liquid handling systems and components.

Jan HJ. Fluiman (member IEEE) was born on March 23, 1938, in Beverwijk, The Netherlands. He received his M.Sc. and Ph.D. degrees in physics from the University of Amsterdam in 1966 and 1970, respectively, in the field of low-te nperature solid-state physics. He joined the University of Twente in 1970. His research interests include magnetic recording, optical waveguide sensors and micromechanics. Since 1982 he has been a full professor of transducer science and first chairman of the Sensors and Actuators Research Unit. Since 1990 he has also been scientific director of the MESA Research Institute, which combines microelectronics and microsystems activities. Dr Fluitman is a member of the MEMS steering committee, the Eurosensors steering comminee, and the World Micro Systems Technology Association.

Satomitsu Imai was born on April 1, 1961, in Chiba, Japan. He received his M.Sc. degree in mechanical engineering from Waseda University in 1987. Thereafter he joined the Mechanical Engineering Research Laboratory, Hitachi, Ltd. His research interests are the development of sliders and suspensions for rigid disk storage devices. 